\title{
PENSANDO 0 PROBLEMA DA ESSÊNCIA DA LINGUAGEM EM SPINOZA
}

\author{
José Fernando da Silva \\ Universidade Estadual de Campinas
}

Resumo: 0 artigo mostra como é possível se examinar o problema da essência da linguagem no pensamento de Spinoza. Primeiro, ele mostra como Spinoza desvincula as noções de essência e universal. Spinoza vincula a noção de essência com a de singularidade. Segundo, o artigo apresenta o elo interno ou necessário que subsiste entre uma essência e a existência em ato do indivíduo. Com essa base, o artigo mostra que a noção de linguagem pertence à classe dos indivíduos, e que a essência de uma linguagem reside em seu uso, isto é, o uso é o traço do esforço de uma linguagem individual para manter sua existência por um tempo indeterminado.

Palavras-chave: linguagem, essência, existência, atividade, uso.

Abstract: The article shows how it is possible to examine the problem of the essence of language in the thought of Spinoza. First, it shows how Spinoza detaches the notions of essence and universal. Spinoza links the notion of essence with that of singularity. Second, the article presents the internal or necessary bond that exists between an essence and the existence in act of an individual. On this basis, the paper shows that the notion of language belongs to the class of individuals, and that the essence of a language lies in its use, that is, use is the trace of the effort of an individual language to maintain its existence indefinitely.

Keywords: language, essence, existence, activity, use.

\section{Apresentação}

Conquanto Spinoza nunca tenha escrito uma reflexão de fôlego sobre a linguagem, ela ocupa um lugar relevante em seu pensamento. Duplamente relevante: ela é, simultaneamente, um elemento fundamental do método 
filosófico empregado no Teológico Político, e é também objeto denunciado como um dos componentes mais decisivos no processo de construção das imagens e das ideias inadequadas constitutivas da realidade humana que a obra spinozista tanto se esforça em denunciar.

Ou seja, de um lado a linguagem é a ferramenta que permite desvelar as origens e o processo de sedimentação de ideias inadequadas na história do povo hebreu. Spinoza assume que a compreensão dos desmazelos que conduziram os hebreus a inventarem o discurso teológico e, consequentemente, um Estado teocrático, imagem que ainda repercute na Holanda de Spinoza, passa pela análise da língua em que o texto das Escrituras foi escrito. O desmascaramento do papel falsificador que a teologia desempenha na Europa do século XVII apenas podia ser efetivado penetrando-se na linguagem das Escrituras, trabalhando com seus enunciados objetivando assimilar o sentido que suas palavras carregavam.

De outro lado, além de ferramenta fundamental à filosofia, a linguagem também se delineia no pensamento spinozista como uma das grandes fontes de aprisionamento do homem. No capítulo V do Teológico Político, dedicado a explicitar o caráter falacioso das cerimônias religiosas, o leitor é conduzido a observar o quanto a linguagem é a mestra que permite a construção de símbolos que sustentam os rituais, que por seu turno são indispensáveis à manutenção de instituições que subjugam os homens. Isso significa que ela é fundamental no esfacelamento de nosso entendimento da realidade, sendo responsável pela sedimentação de superstições e toda sorte de ideias falaciosas alcançadas pela via do exercício do conhecimento imaginativo.

A presença não irrelevante da linguagem no seio do pensamento spinozista é o que instigou a elaboração desse artigo. Ele questiona, portanto, sobre a possibilidade de se obter uma proposta da significação da essência da linguagem no interior do pensamento de Spinoza. O artigo segue o seguinte percurso: primeiro, mostra que Spinoza, contrariando uma longa tradição filosófica, rejeita em seu pensamento a coincidência entre as noções de essência e universal. Segundo, mostra como se delineia em Spinoza a noção de indivíduo e como a noção de essência definida como conatus determina a existência em ato do indivíduo. Encerrando, mostra como é perfeitamente possível incluir a noção de linguagem dentro da esfera daquilo que comporta uma singularidade, de tal sorte que é possível se especular sobre os contornos da essência de uma linguagem. 
Um traço que se destaca no pensamento spinozista é sua não identificação das noções de "essência" e "universal". Desde Aristóteles é lugar comum que o termo "universal" designa o que é comum de muitos, sendo também antiga a tendência de se conceber a essência de uma dada singularidade como uma propriedade geral que é partilhada por outros indivíduos que também são por esta propriedade definidos. De acordo com essa visão, se usamos o termo "gato" para nos referir a dois indivíduos, isso significa que eles partilham da mesma essência, ou seja, ambos participam do(s) mesmo(s) traço(s) que define(m) todos os entes a que chamamos "gato". Hegemônico, cabe ao universal a determinação do que é uma singularidade. Diferentemente dessa tendência, Spinoza sustenta que toda essência é necessariamente singular, não podendo noções gerais ser identificadas como essência de coisas (SPINOZA, 2008a, II p. 37). Essa concepção decorre da posição de Spinoza que vincula numa relação interna a essência e a existência das coisas singulares.

A essência, ou aquilo que define o ser de uma singularidade, está diretamente vinculada com a existência daquilo que ela determina ou define. São inseparáveis. A relação interna ou necessária entre essência e existência se consubstancia de duas maneiras distintas. A primeira e mais fundamental é a que encontramos em Deus. Na Substância absolutamente infinita e eterna encontramos uma identidade entre as noções de essência e existência, de tal sorte que a necessidade de sua (infinita) existência coincide com a natureza de seu ser (SPINOZA, 2008a, Id1). Como a essência divina envolve sua existência, esta é necessariamente eterna, encontrando-se absolutamente alheia a qualquer mensuração temporal (Idem, Id8).

A segunda maneira de consubstanciação dessa relação se dá relativamente a todo restante de coisas que existem, ou seja, os modos finitos da Natureza Naturada. Nos modos finitos não se dá uma relação de identidade entre a essência e a existência, mas tão somente uma relação de inseparabilidade: é a essência da coisa o que determina os contornos de sua potência para existir, findando-se ela também junto com a coisa quando a existência desta última se encerra. "Digo que pertence à essência de uma coisa aquilo que, quando dado, necessariamente a coisa é posta, e que quando retirado, a coisa é necessariamente anulada" (Idem, IId2). Ao contrário de Deus, cuja essência não é alterada pela infinidade de afecções que produz, a essência de um modo finito é afetada pelas afecções do ente cuja existência determina, podendo aumentar ou diminuir sua potência em 
decorrência do tipo de afetividade que constitui a existência da coisa e, em último caso, também desaparecer. No nível modal da ontologia spinozista, lidamos com entes que estão necessariamente envoltos pela noção de alteridade: a essência e a existência de uma coisa singular não apenas dependem da Substância que é causa eficiente imanente de tudo que subsiste, mas também de outras coisas singulares que a afetam e que ela afeta, ou seja, indivíduos do qual ela participa e outras coisas que dela participam. Nas palavras de Alexandre Matheron: "os indivíduos singulares não podem existir senão em comunidade, sob a forma de partes de um universo infinito, no seio do qual tudo age sobre tudo progressivamente" (MATHERON, 1986, p. 19).

Do caráter singular que Spinoza atribui às essências emerge a seguinte questão: que lugar o filósofo holandês reserva aos universais em sua ontologia? A Ética dedica um duplo tratamento aos universais, cindindo-os pela maneira como os dois primeiros graus de conhecimento constroem os termos gerais. Eles são divididos em "termos transcendentais" e "noções comuns". A primeira noção, termos transcendentais, consiste numa universalidade extraída basicamente dos sentidos. Nesse contexto, os universais são elaborações do primeiro gênero de conhecimento, se consubstanciando integralmente como produtos da imaginação. Essa produção se dá do seguinte modo: o corpo humano fornece uma acentuada gama de imagens da realidade empírica à nossa alma. Sobressai-se a tendência de agrupar essas imagens em feixes que exprimem certa concordância entre os homens. Isso significa que a partir de certas ocorrências individuais são construídas noções como "gato", "homem", "joaninha", "galinha d'angola", etc. $\mathrm{O}$ grande problema reside na definição que se dá a esses termos. Esses termos gerais acabam sendo elevados ao estatuto de essências das coisas singulares, ou seja, são caracterizados como sendo a natureza daqueles indivíduos que, conforme dirá Frege alguns séculos depois de Spinoza, caem sob cada um desses conceitos. No entanto, indaga-se Spinoza, o que efetivamente denota a essência do termo geral "homem"?

Por exemplo, os que com frequência consideram com admiração a estatura dos homens compreenderão pelo nome "homem" um animal de estatura ereta; os que estão acostumados a considerar outro aspecto formarão dos homens outra imagem comum, que é um animal que ri ou que é um bípede sem penas, ou que é um animal racional (SPINOZA, 2008a, II p. 40).

A imaginação se encarrega de dar os mais variados contornos ao universal que ela abstrai do campo da experiência. Repleto de ilusões, o 
conhecimento imaginativo não percebe que ainda que os elementos gerais que encontra na realidade subsistam nos indivíduos, não se segue deste fato que eles constituam a essência destes indivíduos. Assim, ainda que seja verdade que um ser humano é bípede sem plumas, ou ainda que seja incontestável que ele possui um intelecto capaz de abstrair noções gerais da natureza, não se segue que a essência de um homem seja o seu bipedismo ou mesmo o seu intelecto. É com os universais produzidos pela imaginação que o homem estabelece, primeiro, perfeições idealizadas e, segundo, motivado pela busca de justificar esses modelos (que em si não passam de produtos da imaginação), finalidades à Natureza que são absolutamente estranhas à sua ordem (SPINOZA, 2008a, IV prefácio).

Do ponto de vista de Spinoza, a outra forma de se pensar os universais consiste em identificá-los como noções comuns que, diferentemente dos termos transcendentais, são produtos do segundo gênero de conhecimento. São elas que fundamentam o conhecimento racional: "as noções ditas comuns e que constituem os fundamentos de nossa capacidade de raciocínio" (Idem, II p. 40). Uma noção comum é uma ideia que expressa determinada composição presente em mais de um modo existente. Elas constituem "aqueles elementos comuns a todas as coisas, e que existem igualmente nas partes e no todo" (Idem, II p38). O termo, portanto, subsome axiomas, fórmulas, leis e conceitos universais produzidos pelo conhecimento científico. Vemos, desse modo, que não é a existência de universais que Spinoza ataca, mas a tendência dos homens a transformá-los em idealidades e gerar um tipo de universalidade abstrata que tão somente contribui para desfigurar o entendimento que estes possuem da realidade. No que tange a esse artigo, importa reter que universais e essências são coisas absolutamente distintas. Nas palavras de Spinoza: "o que é comum a todas as coisas, e que existe igualmente na parte e no todo, não constitui a essência de nenhuma coisa singular" (Idem, II p. 37).

Ora, inicialmente poder-se-ia supor que "linguagem" também expressaria uma noção comum, uma vez que se apresenta como elemento geral presente nas incontáveis manifestações da vida humana. Ocorre que as noções gerais são estruturas que outorgam à Natureza a estabilidade e a fronteira do cenário que possibilita às coisas manterem relações afetivas, e a linguagem é algo que possui uma natureza puramente afetiva. Ela é, como todo ser humano que dela se vale cotidianamente para edificar sua vida, também ininterruptamente afetada e consequentemente modificada pelo imenso campo de acontecimentos socioculturais que trespassa. Em outras palavras: "linguagem" não denota uma noção comum, ou seja, uma espécie de estrutura última que ancoraria as diferentes e múltiplas ocorrências 
linguísticas presentes na realidade modal. Ao contrário, ela se refere a coisas muito distintas que ocorrem em situações e contextos muito diferenciados no complexo âmbito da afetividade modal.

Ainda que Spinoza não tivesse a percepção da amplitude que caracteriza a noção de linguagem (algo que apenas com Wittgenstein será amplamente desvelado pela filosofia), seu Compêndio de Gramática da Língua Hebraica indica que ele tinha consciência do caráter vivo que constitui e determina a linguagem ${ }^{1}$. Uma das coisas que seu Compêndio mostra, é que Spinoza pensava a linguagem e suas múltiplas manifestações histórico-culturais como algo que podia ser perfeitamente integrado à sua concepção de indivíduo. Ele já sabia que "linguagem" denota coisas muito diferentes, agrupando um conjunto aberto de infindáveis ocorrências culturais, todas elas com uma existência finita.

Ora, se no homem a essência é definida como esforço (conatus) para manter a existência, algo que se expressa como desejo, uma questão interessante é qual seria o conatus característico desta atividade multiforme que é a linguagem, algo que se revelasse individualizado em cada manifestação, grande ou pequena, da linguagem. O exame dessa questão começa com uma averiguação do delineamento que Spinoza dá à noção de indivíduo no interior de seu pensamento, e como a existência de um indivíduo é determinada por sua essência.

Uma das características constitutivas da Substância absolutamente infinita e eterna é que ela não está sujeita a qualquer forma de negação. Infinito e eterno, ou seja, livre pela necessidade que envolve sua existência, Deus é pura e absoluta afirmação. Esta característica coincide com sua ilimitada atividade autoprodutora. Na essência de Deus coincidem seu poder e sua potência de agir. Em outras palavras, Deus é causa de si e de todas as coisas, causa eficiente que a tudo movimenta, não havendo qualquer hiato separando o que ele pode fazer e aquilo que ele efetivamente faz.

Por outro lado, qualquer um que direcione seu entendimento para o universo composto pela finitude modal, observa que a atividade afirmativa é inseparável dos limites ininterruptamente postos pela negação (SPINOZA 2010, carta 50, p. 290-1). À livre necessidade que caracteriza a existência de Deus e que faz com que "tudo que concebemos como estando em seu poder,

${ }^{1}$ Este aspecto do Compêndio será exemplificado nas páginas finais do artigo. 
necessariamente é" (SPINOZA, 2008a, I p. 35), contrapõe-se a existência finita dos modos. A existência de um modo finito se mostra sempre dependente de outros modos finitos: "dizemos que um corpo é finito porque sempre o concebemos limitado por outro maior" (Idem, Id2). A alteridade aparece como condição constitutiva da existência dos modos finitos. É esse princípio que fixa para uma coisa singular que ela faz parte de outros indivíduos mais complexos, afetando e sendo afetada por tudo que ocorre no interior destes indivíduos complexos, e sendo também afetada por todas as singularidades de dimensão menor que dela participam como partes. Fixa também que a própria Natureza Naturada em que ela subsiste, condiciona sua existência singular como necessária ou coagida, uma vez que "tudo que existe, existe ou em si mesmo ou em outra coisa" (Idem, Iax1). No patamar daquilo que não existe por si mesmo, isto é, daquilo que existe necessariamente em outra coisa, delineia-se uma forma de existir condicionada: "um modo finito B existe condicionalmente (...): ela se atualiza se e somente se outro modo finito A se atualiza" (MATHERON, 1986, p. 19). O amplo conjunto de relações afetivas em que uma coisa singular se insere, determina sua potência de existir e também assinala o grau de sua capacidade afirmativa da existência.

Nesse patamar da ontologia spinozista, a existência possui uma duração indefinida e que se mostra necessariamente comprometida com a mudança e com a alteridade. O termo "duração indefinida" afasta do âmbito modal do atributo Extensão ideia de uma existência eterna ${ }^{2}$, uma vez que $a$ identidade entre "existência" e "eternidade" ocorre somente em Deus (Idem, Id8), e afasta também a ideia de uma existência com um tempo determinado, pois depende da capacidade individual de uma coisa o período que ela é capaz de preservar em seu ser. $\mathrm{Na}$ verdade, a interdependência que é característica das coisas singulares funda a temporalidade como critério de mensuração da duração da existência modal. É no âmbito da modalidade finita que ganham sentido noções como "passagem, mudança, subsistência, persistência, continuação, perseverança" (LEVY 1998, p. 269).

Fixo-me nesse artigo no atributo Extensão, um das infinitas maneiras de expressão da infinita potência autoprodutora de Deus. Na Extensão, a potência divina se expressa através de modos finitos de natureza corpórea. A singularidade das coisas finitas exprime-se com uma existência determinada (SPINOZA, 2008a, IId7). A determinação da existência é

\footnotetext{
${ }^{2}$ Alexandre Matheron mostra que aos modos finitos do atributo Pensamento aplica-se a noção de eternidade. Ainda que uma essência singular não mais subsista no atributo Extensão, a ideia que a expressa subsiste como "parte atual das ideias infinitas de Deus" (MATHERON, 1986, p. 32).
} 
realizada pela essência da coisa, ou seja, a essência define e determina um sentido que a faz perseverar na existência. No entanto, conforme já mencionamos anteriormente, a essência modal é inseparável da existência, de sorte que quando uma desaparece a outra também é retirada.

A partir da proposição 13 da segunda parte da Ética, Spinoza apresenta uma série de premissas a respeito da natureza dos corpos. Eles existem em ato, estando em constante estado de repouso ou de movimento (Idem, II p.13, ax1). Eles se distinguem pelo tipo de movimento que promovem, e pela maior ou menor velocidade que decorre de suas mudanças (Idem, ax2). Os corpos são interdependentes, ou seja, afetam e são afetados ininterruptamente por outros corpos. Quando diferentes corpos agem unidos promovendo a mesma ação, constituem um indivíduo. Esta unidade é dinâmica, podendo ocorrer que corpos se separem da unidade, ao mesmo tempo em que outros de mesma natureza se agreguem, com isso conservando a natureza do todo. Há, portanto, uma identidade que permanece independentemente das mudanças, condição que garante que sempre falamos do mesmo ente, a despeito do intenso fluxo afetivo que lhe é próprio (Idem, lema 4). Ou, conforme sintetiza Lia Levy: "uma essência modificada é ainda a mesma" (LEVY, 1998, p. 258).

Um modo finito é, ao mesmo tempo, uma reunião determinada de corpos, ou seja, um conjunto de corpos reunidos que seguem uma ordem ou determinação, e também uma parte de um indivíduo, ou seja, um entre diversos corpos que atuam unidos dentro de um indivíduo mais complexo que os envolvem. Os indivíduos que pertencem a um indivíduo mais complexo guardam entre si uma relação intencional, ou seja, são motivados por determinações internas distintas em sua busca de perseverar na existência individual, contribuindo deste modo também para a permanência na existência do indivíduo complexo que os subsome. A dinâmica da afetividade que envolve os modos supõe como algo rotineiro o enfraquecimento de certas partes e o fortalecimento de outras. Esta dinâmica estabelece como fundamental para a continuidade da existência da singularidade complexa que ela mantenha sua determinação para existir. Requer-se, portanto, a permanência de sua essência independentemente do incessante fluxo de afecções que lhe é constitutiva.

Esse quadro geral se aplica perfeitamente a toda infinidade de coisas presentes no universo. Mesmo planetas e estrelas, entes que os antigos tomavam como seres eternos e não sujeitos ao devir, também são seres afetivos que sofrem mudanças e possuem uma existência com uma duração indefinida, ou seja, são também modos finitos. A interdependência interna e externa é condição necessária para a existência de qualquer corpo. Um exemplo: um sapo é constituído de partes duras, moles e fluidas 
(analogamente ao ser humano) (SPINOZA 2008a, II, p. 13, ax3), e depende do equilíbrio de seus órgãos para permanecer na existência. Suas partes (os órgãos de seu corpo) são determinadas a existir com o objetivo de manter a unidade da singularidade anfíbia que as agrupa. Suas partes necessariamente interagem com indivíduos externos. Assim, todas as partes de seu aparelho respiratório são afetadas pelo ar da lagoa em que vive. As partes constitutivas de seu aparelho digestivo são afetadas pelas moscas com que as partes externas do corpo interagem. O sapo é também uma parte de um corpo maior. Ele é parte de algo mais complexo, uma lagoa ou um pântano, ecossistema que lhe fornece as condições fundamentais para sua existência. No entanto, qualquer desequilíbrio que ocorra nesse complexo em que ele insere pode determinar o fim de sua duração. Parte desse ecossistema, o sapo está sujeito a ingerir produtos tóxicos letais, eventualmente ali lançados, pois a lagoa ou o pântano também são partes de um complexo singular maior (SPINOZA, 2008a, III, p. 4).

Ocorre que toda essência é afirmação de uma potência de agir. Toda essência afirma a potência para existir de algo quando o define ou estabelece os critérios que lhe permitem perseverar na existência. Toda essência está vinculada à existência em ato, ou seja, uma existência marcada pela ação. Enquanto a essência divina coincide com a afirmação de uma potência infinita, cuja existência consiste em ser causa de si, em si e por si, autoprodução que também assinala sua eternidade, uma essência modal, a despeito de sua inserção dentro dos infinitos efeitos produzidos por Deus, reproduz numa escala modal a realidade plenamente afirmativa da natureza divina. Se "sem Deus nada existe e nem pode ser concebido" (SPINOZA, 2008a, I, p. 15), então ele é causa eficiente imanente de toda a infinidade de coisas que existem e que dele decorrem de infinitas maneiras (Idem, p16). Toda essência modal, portanto, é determinada a existir por Deus, reproduzindo no âmbito modal o dinamismo de Deus, ou seja, sua absoluta e plena afirmação da existência como potência de agir. Surge nesse ponto a seguinte questão: como se dá a determinação em nível modal que torna as noções de essência e existência uma unidade inquebrantável, de tal sorte que quando retiramos uma, a outra imediatamente também desaparece? Essa relação é esclarecida por Spinoza quando apresenta e examina a essência do homem.

"O esforço (conatus) pelo qual cada coisa se esforça por perseverar em seu ser nada mais é que a sua essência atual" (Idem, III, p. 7). É o impulso, a energia, a força que conduz uma dada singularidade a continuar a existir o que perfaz o cerne de sua essência. Importante reter que essa essência atual (conatus) decorre de uma determinação posta pela atividade 
da essência de Deus. Especificamente no que tange ao ser humano, Spinoza aponta o desejo como sendo aquilo que consiste o conatus humano: "o desejo é a própria essência do homem, enquanto ela é concebida como determinada, em virtude de uma afecção qualquer de si própria, a agir de alguma maneira" (SPINOZA, 2008a, III, definições dos afetos d1).

Ora, já disse anteriormente que toda essência é individual. No caso do homem, tal traço se explica pelo fato do desejo (seu traço definidor) apenas se efetivar com a construção da individualidade que, conforme já vimos, é formada por muitas e heterogêneas partes. No ser humano, é notório que ele se insere em muitas e variadas relações culturais, sociais, políticas, além do amplo espectro de relações que mantém com os fatos da natureza. "Todas as maneiras pelas quais um corpo é afetado seguem-se da natureza do corpo afetado e, ao mesmo tempo, da natureza do corpo que o afeta" (Idem, II, p. 16). A infinidade do campo de afecções que contribuem para a efetividade de uma existência atual the confere uma essência absolutamente única. Não há dois seres humanos com apetites e desejos absolutamente iguais, ou seja, que são idênticos na maneira de afetar e serem afetados pelas respectivas realidades em que se inserem. Aliás, é pouco provável que subsista um ser humano cujos apetites e desejos tenham se mantido os mesmos ao longo de toda sua existência.

A alma humana é um modo de expressão do atributo Pensamento e tem seus limites determinados pela amplitude de interdependência de seu corpo. O ser atual da alma humana é o complexo de ideias que ela constrói a respeito de uma coisa singular existente em ato, a saber, o seu corpo, ou melhor, "um modo definido da Extensão, existente em ato, e nenhuma outra coisa" (Idem, II, p. 13). Há, portanto uma unidade entre a alma e o corpo (Idem, II, p. 7). Não se trata de dois seres distintos em que um comanda o outro (como um comandante de navio realiza com sua embarcação), nem tampouco de dois modos de ser que subsistem numa relação paralela. Tratase tão somente de uma singularidade, cujo ato de existência se expressa simultaneamente de diferentes modos (corpórea ou psiquicamente). Ora, todo corpo é uma união de outros corpos, e também existe na direta proporção em que se mostra apto a interagir, afetando e sendo afetado por corpos externos. "Não só o corpo está exposto à ação de todos os outros corpos exteriores que o rodeiam e dos quais precisa para conservar-se, regenerar-se e transformar-se, como ele próprio é necessário à conservação, regeneração e transformação de outros corpos" (CHAUÍ, 2011, p. 73). A alma constrói uma complexa rede de ideias que exprimem psiquicamente tudo que o corpo vivencia, construindo também uma ideia de si própria, da realidade e da inserção dela e de seu corpo nos contornos da realidade que consegue delinear. 
A singularidade de um homem é, necessariamente, algo dinâmico. Como todos os demais modos finitos, o ser humano é necessariamente afetivo. A essência enquanto esforço para perseverar na existência é esforço para sentir e viver afecções que produzam alegria (SPINOZA 2008a, III, definição dos afetos d3). Alegrias aumentam a realidade do indivíduo, expandindo-a na direta proporção em que aumenta sua potência de agir. Por outro lado, tristezas enfraquecem o ânimo do indivíduo, ou seja, diminuem a potência para existir, e com isso mingua as dimensões de sua realidade. É a essência que garante a unidade que subsiste no devir e que se alimenta da dinâmica e ininterrupta afetividade. Ao longo de uma existência individual, as afecções que se sucedem faz com que certos desejos e apetites sejam abandonados e os substituamos por outros. A essência vai se lapidando e buscando caminhos que a potencialize. Se a essência humana é o desejo, ela alimenta a existência do indivíduo a viver ininterruptamente a afetividade do mundo. Além disso, a (indefinida) duração de um ser humano é algo diretamente condicionado pelas relações que sua complexa singularidade é capaz de manter com os diferentes indivíduos com que se relaciona. De sua capacidade ou não de alimentar saudavelmente as muitas partes de seu ser (órgãos físicos, complexidade psíquica, racionalidade, além das múltiplas teias de relações de que participa - familiares, culturais e políticas -) também decorre o incognoscível período de sua existência. A ininterrupta e múltipla afetividade humana torna a duração de sua existência sujeita à sua capacidade de manter intactas as determinações de sua existência. Para isso, é fundamental o grau de entendimento que um indivíduo possui das relações afetivas de que participa. Assim, o equilíbrio interno dos órgãos está sempre sendo afetado por fatores externos, de tal sorte que paixões tendem a fazer com que órgãos se desestabilizem e obriguem outros órgãos a alterarem os traços de seu funcionamento natural, objetivando restabelecer o equilíbrio no corpo. Enquanto parte de diferentes singularidades ou indivíduos, um homem constantemente coloca em risco sua própria existência em decorrência das afecções que mantém com variados indivíduos que também se agregam no interior destes diferentes e complexos indivíduos no papel de parte.

Delineado esse quadro, examino a seguir em que sentido a concepção spinozista da essência como determinação de uma existência em ato se aplica à noção de linguagem. 
Para traçar o que caracteriza a potência afirmativa de uma dada linguagem, ou seja, aquilo que a coloca como algo com uma existência efetiva porque afetiva, é interessante começar listando o que se apresenta como próprio da essência de um modo finito, em particular dos modos finitos constitutivos do atributo Extensão. Já foi dito que qualquer corpo é constituído de partes que se caracterizam como corpos menores, cuja subsistência obedece a uma determinação que define o próprio corpo em que se integram. Também expus anteriormente que um corpo singular qualquer é também (de diferentes maneiras) parte de outros corpos complexos (um ser humano, p.ex., pode ser parte de uma escola, de uma empresa, de uma aldeia ou de um Estado etc.). Cada coisa singular tem uma essência própria, fator que determina sua dinâmica de existência. É a essência da coisa que delimita os traços que lhe conferem unidade e identidade. A essência de um indivíduo ou singularidade é a potência interna que determina sua existência em ato. Essa potência visa sempre a afirmação do ser, e somente desaparece com o término da própria coisa que ela determina a existir. Este desaparecimento decorre sempre de causas externas à própria essência da coisa. A questão que se coloca nesse ponto é a seguinte: como esses traços podem ser projetados sobre uma linguagem?

Uma metáfora extremamente feliz de Wittgenstein é um bom ponto de partida para vermos como esses traços se projetam sobre qualquer linguagem. Examinando o que é uma linguagem, Wittgenstein a compara com uma cidade:

$\mathrm{O}$ fato de as linguagens (2) e (8) consistirem apenas de comandos não deve perturbá-lo. Se você quer dizer que elas não são completas, então pergunte-se se nossa linguagem é completa; - se o foi antes que lhe fossem incorporados o simbolismo químico e a notação infinitesimal, pois estas são, por assim dizer, os subúrbios de nossa linguagem (e com quantas casas ou ruas, uma cidade começa a ser cidade?). Nossa linguagem pode ser considerada como uma velha cidade: uma rede de ruelas e praças, casas novas e velhas, e casas construídas em diferentes épocas; e isto tudo cercado por uma quantidade de novos subúrbios com ruas retas e regulares e com casas uniformes (WITTGENSTEIN, 1979, §18).

Comparando-se uma linguagem com uma cidade, de modo similar ao que propõe Wittgenstein, se observa que é constituída por partes muito 
heterogenias e dinâmicas que surgem, desaparecem, se reformulam e se regeneram. Desse ponto de vista, com o termo "linguagem" se procura designar singularidades de diferentes dimensões, do mesmo modo como ocorre com o termo "cidade" ("cidade" se aplica tanto a pequenas cidades, vilarejos que agrupam uma pequena concentração de seres humanos, quanto se aplica à designação de grandes aglomerados humanos como as cidades de Campinas ou São Paulo). Com "linguagem" expressamos uma infinidade de coisas muito diferentes: de comandos específicos que norteiam a interação entre dois ou mais profissionais em seu dia-a-dia, ao conjunto léxico e fonético de um grande aglomerado de pessoas que vivem e expressam com sua linguagem, tácita ou explicitamente, a visão de mundo que lhes é comum; do vocabulário específico que desempenha papel fundamental à efetividade de variadas e idiossincráticas atividades culturais (um sarau literário, uma roda de choro, uma roda de samba etc.), ao vocabulário e regras de conduta que norteiam o pomposo ato de batizar um navio. Uma linguagem se mostra constituída por palavras, frases, sinais de pontuação e regras de aplicação que tanto se consubstanciam de modo formal quanto sob a forma de regras tácitas sedimentadas em silenciosos gestos e ações dos participantes da prática linguística. Além disso, toda linguagem é também parte de uma ou mais engrenagens (corpos complexos): um nicho cultural, uma grande e milenar cultura, uma família etc. Nesse sentido, as diferentes atividades linguísticas que um indivíduo vivencia se esboçam como elemento estruturante da nervura que o ancora, pois se configuram como elemento fundamental para que a alma apreenda e construa as dimensões do mundo que se edifica a partir das afecções que o corpo experimenta.

As relações internas e externas que se processam numa linguagem constituem sua existência em ato e expressam, por mais ampla que seja a gama de modificações afetivas que ela sofra, ainda subsiste uma unidade e uma identidade. Spinoza quando reflete sobre a linguagem o faz ainda preso ao termo técnico que designamos "língua". Preocupado com os amplos efeitos fragmentadores e destrutivos gerados pela intervenção de rabinos e gramáticos na língua hebraica há centenas de anos atrás, Spinoza esboça um trabalho que delineia a essência da língua hebraica e, consequentemente, o elemento determinante à existência de toda e qualquer língua. E aqui, é importante notar que o termo técnico "língua" (em especial depois de Saussure) expressa uma das infinitas atividades que caem sob o termo "linguagem".

Spinoza formulou em relação à língua a seguinte questão: qual seria a potência interna que anima ou impulsiona uma língua a existir concreta e 
efetivamente na realidade extensa? Sua resposta, conquanto tácita (não se encontra explicitamente formulada em sues livros) é absolutamente revolucionária e coerente com seu pensamento: o uso. Revolucionária porque antecipou a formulação amplamente desenvolvida por um dos principais expoentes da filosofia no século XX: Wittgenstein. Toda reflexão de Spinoza sobre a língua hebraica mostra que o conatus de uma língua é seu uso. É com ele que enquanto singularidade complexa ela expressa sua existência em ato. É nele que se mostra todo o dinamismo que a faz constantemente se renovar e perseverar em seu ser. O uso ratifica e reforça a determinação de perseverar em seu ser que uma língua mostra através do hábito sedimentado cotidianamente por aqueles que a praticam. $\mathrm{O}$ uso renova a língua, combatendo traços degenerativos com a introdução de novas partes e determinações. É no uso de uma língua que observamos sua capacidade de subsistir, sobrevivendo a neologismos e a prática de agregar arbitrariamente (sem a chancela primeira do hábito) palavras extraídas de outra língua (própria a uma cultura estranha, e muitas vezes absolutamente antagônica à cotidianidade daqueles que a praticam). Por fim, é o uso, ou melhor, a ausência de uso de uma língua, o que determina seu processo de desaparição.

Eis alguns momentos da obra spinozista que referendam essa hipótese. Na carta 75, a Oldenburg, Spinoza escreve: "você pensa que o Evangelho de João e as Epístolas aos Hebreus se opõem ao que eu disse porque mede as línguas orientais pelo modo de falar europeu. Ainda que João tenha escrito seu evangelho em grego, ele hebraíza" (SPINOZA, 2010, carta 75 , p. 368-9). O que Spinoza pretende dizer a Oldenburg com a sentença "João hebraíza"? Que este, conquanto escrevesse em língua grega, dado o interesse que tinha de divulgar o conteúdo de seu relato, pensava e articulava seu discurso em hebraico ${ }^{3}$. A ideia ou conjunto de ideias que a alma de João possuía de todas as afecções e afetividades experimentadas por seu corpo e que formavam sua visão de mundo, possuíam como base sua vivência numa família hebraica e numa comunidade de amigos e pessoas que tinham como língua-mãe a língua hebraica. Apreende-se dessa passagem, que para Spinoza o hábito que se mostra no uso de uma língua

\footnotetext{
${ }^{3}$ Philippe Cassutto defende que Spinoza também hebraiza, ou seja, que sua filosofia, ainda que vise 0 universal, "não é menos enraizada em sua (suas) cultura (s). (...) 0 hebreu foi o tipo de solo que possibilitou que seu pensamento se desenvolvesse até atingir a altura que ele alcançou (pour atteindre les sommets qu'on lui connaît)" (CASSUTTO 1999, p. 236). Em seu texto, Cassutto procura rebater a identificação de Spinoza como um judeu, alegando que o judaísmo se caracteriza pela lei escrita pelo rabinato, por oposição à tradição oral que antecede à lei escrita fixada pelos gramáticos de origem judaica que desconsiderou a amplitude da cultura hebraica.
} 
forma nervuras internas que alicerçam o pensamento e determinam as atitudes dos falantes que a partilham. Nesse sentido, os falantes de uma língua podem ser pensados, do ponto de vista spinozista, como partes dela, no sentido de estarem sujeitos às determinações (semântico-culturais) construídas e absorvidas através do hábito ou vivência no interior da prática dessa língua, similarmente como ocorre com as partes de nosso corpo.

No Compêndio de Gramática da Língua Hebraica, texto inacabado do autor, Spinoza se propôs escrever uma gramática da língua hebraica, uma vez que todas as gramáticas até então existentes seriam gramáticas do hebraico das Escrituras, e não da língua efetiva sedimentada nos hábitos e costumes dos antigos hebreus (SPINOZA, 2006, p. 80). Claramente, Spinoza alude a uma essência da língua hebraica brutamente enfraquecida por alguns hebreus, os gramáticos, que assim atuaram motivados por causas externas, a saber, os interesses políticos de outros povos e o deslumbramento exercido sobre eles pela forma de apresentação e estruturação de línguas estranhas ao hebraico praticado e efetivado na cotidianidade pelo povo hebreu.

A mesma posição Spinoza defende no Teológico-Político, em especial no capítulo VII, lugar em que delineia as regras apropriadas para se construir uma interpretação das Escrituras. Nesse capítulo, Spinoza mostra e explora a ampla possibilidade de manipulação do sentido do texto bíblico. A sistematização realizada pelos gramáticos, introduzindo vogais e acentos numa língua absolutamente oral, tornou possível aos teólogos "extorquir dos Livros Sagrados as suas próprias fantasias e arbitrariedades" (SPINOZA 2008b, p. 114).

Marilena Chauí destaca que no capítulo I do Teológico-Político, Spinoza realiza uma análise filológica em que é recorrente o verbo hayah ("ser" em hebraico). Em seu estudo sobre as relações entre linguagem e liberdade no contradiscurso spinozista, Chauí mostra que hayah é um verbo predominantemente de ação, significando "dever e agir, tornar-se, fazer, vira-ser e produzir" (CHAUÍ 1984, p. 99). Se hayah designa existência, o é no sentido de uma efetividade. Isso faz com que o célebre Eheyeh Asher eheyer (Sou aquele que sou), que caracteriza Deus como potência absoluta que age sem qualquer mediação entre suas ações e aquilo que produz, seja algo distante do tetragrama YHWH. Este último, não vai além de uma produção da religião mosaica (essencialmente teocrática), que transformou $o$ significado de "Deus" de pura e absoluta efetividade ("Sou aquele que sou") em "Senhor". "Assim, aquilo que era parte espontânea da língua e de sua etimologia sofre uma alteração de sentido cuja causa não é linguística" 
(CHAUÍ 1984, p. 102). Eis, novamente, a ideia de causas externas à essência da língua contribuindo para o enfraquecimento de sua potência.

Concluindo: a força do hábito que uma língua configura a maneira que orienta e determina como refletimos sobre a vida (algo que Spinoza indica com "João hebraíza"), e o enfraquecimento da potência da língua resultante de ações promovidas por forças externas a uma língua, mostram que em Spinoza já se encontra a percepção do lugar determinante que o uso ocupa na existência atual de uma língua e, por extensão, de uma linguagem. Percebemos, deste modo, que já se encontra latente no pensamento de Spinoza o célebre mote contemporâneo que assume o uso como a essência da linguagem, agregando-se a outros fatores que mostram a atualidade de sua obra.

\section{Referências}

CASSUTTO, Philippe. Spinoza hébraïzant: l'hébreu dans le 'Tractatus theologico-politicus' et le 'Compendium grammatices linguae hebraeae'. Paris-Louvain: Peeters, 1999.

CHAUÍ, M. Da realidade sem mistérios ao mistério do mundo: Espinosa, Voltaire, Mearleau-Ponty. São Paulo: Brasiliense, 1984.

LEVY, L. O autômato spiritual: a subjetividade moderna segundo a Ética de Espinosa. Porto Alegre: L\&PM, 1998.

MATHERON, A. Individu et commaunité chez Spinoza. Paris: Les Editions de Minuit, 1986.

SPINOZA, Benedictus de. Abrégé de gramaire hébraïque. Paris: Vrin, 2006.

. Correspondance. Paris: Flamarion, 2010.

. Ética. 2. ed. Belo Horizonte: Autêntica, 2008a.

2008 b.

. Tratado Teológico-Político. 2. ed. São Paulo: Martins Fontes,

WITTGENSTEIN, L. Investigações Filosóficas. 2.ed. São Paulo: Abril Cultural, 1979. (Col. Os Pensadores). 